\title{
Verticillium Wilt of Skullcap and Potential for Pathogen Dissemination via Seeds and Stems
}

Jeremiah K. S. Dung, Washington State University, Pullman; Lindsey J. du Toit, Washington State University Mount Vernon NWREC, Mount Vernon; and Dennis A. Johnson, Washington State University, Pullman

\begin{abstract}
Dung, J. K. S., du Toit, L. J., and Johnson, D. A. 2011. Verticillium wilt of skullcap and potential for pathogen dissemination via seeds and stems. Plant Dis. 95:1147-1152.

A commercial skullcap (Scutellaria lateriflora, family Lamiaceae) crop with wilted and necrotic plants was examined in Washington State in 2008. Three fungal isolates were obtained and identified as Verticillium dahliae based on morphology and sequencing of the internal transcribed spacer DNA region. All three skullcap isolates caused typical Verticillium wilt symptoms on skullcap and two peppermint cultivars. Inoculations of skullcap with the $V$. dahliae isolates from skullcap and an isolate from peppermint resulted in severe symptoms and a 21 to $78 \%$ reduction in aboveground biomass. Isolates from skullcap caused severe symptoms on the susceptible peppermint 'Black Mitcham' and reduced yield by up to $82 \%$. One skullcap isolate caused

severe symptoms on the moderately resistant 'Redefined Murray' in three of four trials and reduced biomass up to $71 \%$ compared with noninoculated control plants. The pathogen was recovered from 43 to $69 \%$ of skullcap stems from plants inoculated with skullcap or peppermint isolates, and was isolated from $2.5 \%$ of seed harvested from skullcap plants inoculated with the peppermint isolate of $V$. dahliae. This is the first report of $V$. dahliae infecting skullcap, and the first demonstration of $V$. dahliae isolates from skullcap and peppermint causing symptoms on both hosts, as well as the seedborne nature of $V$. dahliae in skullcap.
\end{abstract}

Skullcap (Scutellaria lateriflora) is a native, North American, herbaceous perennial in the family Lamiaceae $(20,32)$. The flowers and leaves are used in medicinal extracts and teas for anti-inflammatory and anti-spasmodic treatments $(5,44,45)$. Skullcap is a specialty crop with a relatively narrow niche market. As a result, an organic skullcap crop can be highly profitable due to limited, small-scale production and the perennial nature of the crop. Despite the long-term use of skullcap and commercial interest in the plant, there has been little research regarding diseases that affect skullcap. The United States Department of Agriculture-Agricultural Research Service Fungal-Host Index (19) lists several reports of pathogens affecting $S$. lateriflora in North America, including Erysiphe spp., a Microsphaera sp., Phyllosticta decidua (Phoma exigua var. exigua), and Septoria scutellariae. Other pathogens have been recorded from other Scutellaria spp. around the world (19).

Verticillium dahliae (Kleb.) is a soilborne fungus and a primary causal agent of Verticillium wilt. The fungus has a wide host range and can infect over 200 dicotyledonous plants $(1,36)$. Verticillium wilt has been documented on several hosts in the family Lamiaceae, including the genera Agastache, Calamintha, Hedeoma, Lamium, Monarda, Ocimum, Pycnanthemum, and Salvia $(6,10,18,21,41,42)$ and genera Clerodendrum, Prostanthera, Rosmarinus, and Satureja (19). One of the most important agricultural crops in the Lamiaceae affected by Verticillium wilt is mint (Mentha spp.), a crop valued at over $\$ 70$ million in Washington State in 2009 (33). Fields of peppermint (Mentha $\times$ piperita L.)

\section{Corresponding author: J. K. S. Dung, E-mail: dungj@wsu.edu}

PPNS number 0554, Department of Plant Pathology, College of Agricultural, Human, and Natural Resource Sciences Agricultural Research Center, Project No. WNP00678, Washington State University, Pullman, WA 991646430.

Accepted for publication 9 May 2011.

doi:10.1094/PDIS-01-11-0014

(C) 2011 The American Phytopathological Society and Scotch spearmint (Mentha $\times$ gracilis Sole) can be severely affected by Verticillium wilt whereas another commercially grown species, native spearmint (Mentha spicata L.), is resistant $(7,27)$. Verticillium wilt symptoms in mint vary but can include anthocyanescence, bronzing, curling of the apical leaves, chlorosis, stunting, wilt, necrosis, and premature senescence (24). Losses due to decreased oil production and stand reduction can worsen over subsequent seasons of the perennial crop (29). Most $V$. dahliae isolates collected from mint belong to vegetative compatibility group (VCG) 2B and are highly aggressive on mint compared with other hosts. The occurrence of a mint pathotype of $V$. dahliae has been previously suggested $(15,16,22)$.

A commercial crop of skullcap with foci of plants exhibiting unilateral wilting, chlorosis, and necrosis was examined during the summer of 2008 in the Columbia Basin of Washington State. The field was certified for organic production and peppermint, a crop known to be susceptible to Verticillium wilt, had been grown in the field in 2003. Three fungal isolates were obtained from the roots, crowns, and stem sap of symptomatic skullcap plants collected in 2008, and identified as V. dahliae based on morphological characteristics. The primary objectives of this study were to verify the morphological identification of the fungal isolates by sequencing the internal transcribed spacer (ITS) region of DNA, and complete Koch's postulates to confirm the pathogenicity of $V$. dahliae on $S$. lateriflora. Given that the field with the affected skullcap crop was previously cropped to peppermint, and most $V$. dahliae isolates from mint belong to VCG $2 \mathrm{~B}$, a third objective was to characterize the skullcap isolates by VCG and evaluate the aggressiveness of $V$. dahliae isolates from skullcap and mint on both crops. Finally, because skullcap growers often propagate their own planting material via seed and shoots for subsequent crops, a fourth objective was to determine the potential for dissemination of the pathogen via infected seed and stems.

\section{Materials and Methods}

Fungal isolations and morphological identification. Attempts were made to isolate $V$. dahliae from the stems, stem sap, and roots of symptomatic skullcap plants sampled from an organic skullcap crop in the Columbia Basin of Washington State in 2008. Stem sections 3 to $4 \mathrm{~cm}$ long were dipped in $95 \%$ ethyl-alcohol and 
surface-sterilized in $0.5 \% \mathrm{NaOCl}$ for $3 \mathrm{~min}$. The stem sections were then plated onto sterile Whatman filter paper moistened with sterile distilled water $\left(\mathrm{sdH}_{2} \mathrm{O}\right)$ and incubated for 14 days at 22 to $23^{\circ} \mathrm{C}$. In addition, stem sap from 3- to 4-cm-long stems was expressed in sample bags using a vice with $1 \mathrm{ml}$ of $\mathrm{sdH}_{2} \mathrm{O}$ added to the bag. A 100- $\mu$ l aliquot of the diluted sap was spread onto each of three replicate petri plates containing NP-10 agar medium (11). Skullcap root sections were incubated for 14 days in a moist chamber at 22 to $23^{\circ} \mathrm{C}$. All samples were visually inspected for fungi using a dissecting microscope. Three fungal subcultures ('VSP 08-33 A3', 'VSP 08-33 C4', and 'SL1-1') were identified morphologically as $V$. dahliae. Cultures were maintained on $1 \%$ potato dextrose agar (PDA) consisting of PDA (10 g/liter) and agar ( $15 \mathrm{~g} /$ liter). Cultures were stored on sterile filter paper at $-20^{\circ} \mathrm{C}$.

Molecular identification. DNA was extracted from fungal cultures grown in Czapek-Dox broth using a glass bead breakage method (14). Quantity and quality of DNA was measured using a spectrophotometer and agarose gel electrophoresis. The ITS region of DNA (ITS1-5.8S-ITS2) of the Verticillium isolates was amplified by polymerase chain reaction (PCR) assay with primers ITS1 $\left(5^{\prime}\right.$-TCCGTAGGTGAACCTGCGG- $\left.3^{\prime}\right)$ and ITS4 (5'-TCCTCC GCTTATTGATATGC-3') (43). The PCR reaction mix included 10 ng of template DNA, $1 \times$ GoTaq Reaction Buffer (Promega Corp., Madison, WI), $8 \mathrm{mM} \mathrm{MgCl}_{2}, 1.28 \mathrm{mM}$ dNTPs, $400 \mathrm{nM}$ each primer, and $1 \mathrm{U}$ of Taq polymerase in a $25-\mu \mathrm{l}$ reaction. Amplifications were performed in a Bio-Rad DNA Engine thermocycler (Bio-Rad Laboratories, Hercules, CA), using the following cycling parameters: an initial denaturation at $94.8^{\circ} \mathrm{C}$ for $2 \mathrm{~min}$, followed by 35 cycles of denaturing at $94^{\circ} \mathrm{C}$ for $30 \mathrm{~s}$, annealing at $55^{\circ} \mathrm{C}$ for $30 \mathrm{~s}$, and extension at $72^{\circ} \mathrm{C}$ for $90 \mathrm{~s}$. A final extension was performed at $72.9^{\circ} \mathrm{C}$ for $5 \mathrm{~min}$. A $5-\mu \mathrm{l}$ aliquot of the final PCR product for each isolate was electrophoresed on a $2 \%(\mathrm{wt} / \mathrm{vol})$ agarose gel to check the size and concentration of the PCR product. Two 3- $\mu$ l aliquots of the PCR product were each treated with $1 \mu \mathrm{l}$ of ExoSAP-IT (USB Corporation, Cleveland, $\mathrm{OH})$ and incubated in a thermocycler at $37^{\circ} \mathrm{C}$ for $15 \mathrm{~min}$ followed by $15 \mathrm{~min}$ at $80^{\circ} \mathrm{C}$. The treated aliquots were diluted to $15 \mu$ with $\mathrm{sdH}_{2} \mathrm{O}$ containing $8 \mathrm{pmol}$ of either primer, and sequenced in both directions at Elim Biopharmaceuticals, Inc. (Hayward, CA). ITS sequences from the three isolates of skullcap were viewed in BioEdit 7.0.5.3 (23) and aligned using CLUSTAL W (39). A BLAST search was performed to compare target sequences with sequences in the GenBank database (3).

Completion of Koch's postulates. The three $V$. dahliae isolates from skullcap (VSP 08-33 A3, VSP 08-33 C4, and SL1-1) were used for pathogenicity tests. Skullcap plants were propagated by rooting 7-cm-long cuttings taken from belowground rhizomes in Sunshine LC1 peat-based potting mix (SunGro, Bellevue, WA). Two cultivars of peppermint (Mentha $\times$ piperita), 'Black Mitcham' (susceptible to Verticillium wilt) and 'Redefined Murray' (moderately resistant to Verticillium wilt), were used as control treatments. Mint plants were propagated by rooting 7-cm-long cuttings taken from aboveground stems in LC1 potting mix. Conidial suspensions of $V$. dahliae isolates VSP 08-33 A8, VSP 08-33 C4, and SL1-1 were prepared by inoculating $100 \mathrm{ml}$ of Czapek-Dox broth (MP Biomedicals, Solon, $\mathrm{OH}$ ) with colonized agar plugs taken from cultures of the single-spore isolates grown on 1\% PDA. The liquid cultures were incubated at $125 \mathrm{rpm}$ on a shaker at 22 to $23^{\circ} \mathrm{C}$ in the dark for 7 to 10 days. Each conidial suspension was strained through four layers of cheesecloth to remove mycelium. Conidial concentration was quantified with a hemacytometer and adjusted to $1 \times 10^{6}$ conidia/ml by adding $\mathrm{sdH}_{2} \mathrm{O}$. The plants were soaked in $50 \mathrm{ml}$ of conidial suspension for $1 \mathrm{~min}$, with the control treatment consisting of plants soaked in $\mathrm{sdH}_{2} \mathrm{O}$. Plants were then transplanted into $10-\mathrm{cm}$-wide $\left(600-\mathrm{cm}^{3}\right)$ square pots filled with LC1 potting mix. Each treatment combination was replicated six times and the experiment was repeated once. Plants were arranged in a randomized complete block design in the greenhouse and natural light was supplemented to achieve a photoperiod of at least 15 h/day when necessary. Disease severity was evaluated 4,5 , and 7 weeks postinoculation (wpi) during the first trial and 4, 6, and 7 wpi during the second trial, using a similar disease severity index (DSI) that has been used for Verticillium wilt severity ratings on mint (16): $0=$ no visible symptoms; $1=$ mild chlorosis on $<10 \%$ of the plant; $2=$ distinct chlorosis on 10 to $25 \%$ of the plant; $3=$ asymmetrical apical growth, with chlorosis on 25 to $50 \%$ of the plant or stunting $(<75 \%$ the height of noninoculated control plants); $4=$ chlorosis on $\geq 50 \%$ of the plant or severe stunting ( $<50 \%$ the height of noninoculated control plants); $5=$ necrosis on $\geq 50 \%$ of the plant; and $6=$ dead or nearly dead plant. Disease severity index ratings were converted to area under the disease progress curve (AUDPC) values using the following formula: $\Sigma_{i}^{n-1}\left(\left[Y_{i}+Y_{i+1}\right] / 2\right)\left(t_{i+1}-t_{i}\right)$, where $Y_{i}=$ cumulative disease severity at the $i$ th observation, $t_{i}=$ time (days postinoculation) at the $i$ th observation, and $n=$ number of observations. Analysis of variance (ANOVA) was carried out using PROC MIXED in SAS (version 9.2; SAS Institute, Cary, NC) and comparisons of AUDPC were performed using Tukey's honest significant difference test.

Aboveground plant material was harvested at the conclusion of each trial and air dried for 2 weeks at $23^{\circ} \mathrm{C}$, and dry biomass recorded. Dry plant biomass (yield) was converted to a yield ratio using the following formula: yield ratio $_{n(x)}=$ yield $_{n(x)} /$ mean yield $_{\operatorname{control}(x)}$, where $n(x)=$ yield for of a particular host plant $(x)$, and control $(x)=$ the mean yield of noninoculated control plants of the same host $(x)$. A yield ratio $<1$ indicates a reduced yield (dry biomass) compared with the mean yield of the noninoculated control plants. ANOVA and means comparisons were performed as described above for AUDPC. Linear regression was performed to determine the association between yield ratio and AUDPC using PROC REG in SAS.

VCG analysis. VCG testing was performed essentially as described by Joaquim and Rowe (25), with a few modifications. Chlorate-resistant mutants (nitrate-nonutilizing [nit] mutants) were obtained by culturing $V$. dahliae isolates on $1.5 \%$ water agar (Difco Laboratories, Detroit, MI) amended with dextrose ( $2 \mathrm{~g} /$ liter $)$ and potassium chlorate $(50 \mathrm{~g} / \mathrm{liter})$. Plates were incubated for 2 to 4 weeks at room temperature $\left(22\right.$ to $23^{\circ} \mathrm{C}$ ), and nit mutants were obtained from rapidly growing sectors. Each nit mutant was paired with a known Nit1 and NitM VCG tester strain on minimal media at least twice. The tester strains used for each VCG were V-44 (VCG 1), T9 (VCG 1A), PH (VCG 2A), 115 (VCG 2B), 70-21 (VCG 3), BB (VCG 4A), S39 (VCG 4B), and MT (VCG 6). Plates were checked for complementation after 2 to 3 weeks and rated as no complementation (no reaction), weak complementation (sparse growth of aerial hyphae but no microsclerotia formation), moderate complementation (sparse growth of aerial hyphae and sparse microsclerotia formation), or strong complementation (full wildtype growth with growth of aerial hyphae and microsclerotia formation). Only tests resulting in strong complementation were interpreted as a positive result but all reactions were recorded.

Aggressiveness assays. Skullcap, Black Mitcham peppermint, and Redefined Murray peppermint plants were propagated as described above and transplanted to $10-\mathrm{cm}$-wide square pots filled with LC1 potting mix. Conidial suspensions of $V$. dahliae isolates VSP 08-33 A8, VSP 08-33 C4, and SL1-1 were prepared as described above. In addition, $V$. dahliae isolates 109, obtained from peppermint and highly aggressive on Black Mitcham peppermint $(16,28)$, and 653 , obtained from potato and causing only mild symptoms on Black Mitcham peppermint $(15,16)$, were used. Plants were inoculated by applying a soil drench of each conidial suspension at a final concentration of $10^{5} \mathrm{CFU} / \mathrm{cm}^{3}$ of potting medium. Each treatment combination was replicated four times and plants were arranged in the greenhouse using a randomized complete block design. The experiment was repeated once. Verticillium wilt symptoms were evaluated at approximately 5, 6, and 8 wpi Disease assessments, AUDPC and yield ratio calculations, ANOVA, and linear regression were performed as described above.

Stem and seed assays. Two 4-cm-long basal stem sections were taken from each plant at the conclusion of each trial described above. Stem sections were sampled prior to harvesting for biomass (yield) assessment, as described above. Fresh stem sections were 
dipped in $95 \% \mathrm{EtOH}$, surface-sterilized in $0.5 \% \mathrm{NaOCl}$ for $1 \mathrm{~min}$, and plated onto sterilized Whatman filter paper moistened with $\mathrm{sdH}_{2} \mathrm{O}$. Plates were incubated for 14 days in the dark and checked for $V$. dahliae conidiophores and microsclerotia formation. The fungus was subcultured from the stems onto 1\% PDA to confirm identification.

Following yield measurements, seed pods were collected from the plants in each treatment, and the seed was removed from the pods and surface-sterilized by rinsing for $10 \mathrm{~s}$ with $0.5 \% \mathrm{NaOCl}$. Seed were then rinsed with $\mathrm{sdH}_{2} \mathrm{O}$ for $10 \mathrm{~s}$ and air dried. In total, 100 surface-sterilized seeds were plated onto NP-10 agar to assay for seedborne infection by $V$. dahliae. An additional 100 seeds were plated on Whatman filter paper moistened with $\mathrm{sdH}_{2} \mathrm{O}$ to assay for both seedborne $V$. dahliae and germination rate. Because peppermint hybrids do not produce fertile seed of any commercial value (31), only seed from skullcap plants were harvested and assayed.

\section{Results}

Molecular identification. Three fungal isolates were obtained from symptomatic skullcap plants sampled from the organic skullcap crop in 2008. The three isolates were identified as $V$. dahliae based on the formation of verticillate, hyaline conidiophores, and conidial morphology and the production of microsclerotia. The fungi lacked chlamydospores or yellow pigment in culture on $1 \%$ PDA, ruling out $V$. tricorpus. Amplification of the ITS1-5.8S-ITS2 regions of isolates VSP 08-33 A3, VSP 08-33 C4, and SL1-1 resulted in PCR products 486, 467, and 510 bp in length, respectively. When aligned, the overlapping regions of the three sequences were identical and exhibited high identity ( $\geq 99 \%)$ with ITS sequences of $V$. dahliae available in GenBank. The three sequences were deposited into GenBank (accessions HQ692908 to HQ692910).

Completion of Koch's postulates. All skullcap V. dahliae isolates caused symptoms on skullcap plants typical of Verticillium wilt symptoms found on mint, including unilateral chlorosis, necrosis, stunting, wilting, and senescence. Similar symptoms were observed on Black Mitcham peppermint, a known host of $V$. dahliae. Results for the two trials were not significantly different $(P=$ 0.6210); therefore, AUDPC data were combined for analysis. Host, isolate, and host-isolate interactions were significant at $P<$ $0.0001, P=0.0024$, and $P=0.0146$, respectively. Although infection by isolate SL1-1 caused the greatest AUDPC on both cultivars of peppermint, differences among isolates were not significant within hosts (Fig. 1A).

$V$. dahliae isolates VSP 08-33 C4 and SL1-1 caused significant $(P<0.0001)$ reductions in yield ratios compared with noninoculated control plants in both trials (Fig. 1B). Disease severity and yield effects of isolate VSP 08-33 A3 were not significantly different than those of the control plants during the second trial but still reduced yields by an average of $27 \%$ among the three hosts. Inoculation with isolate SL1-1 resulted in the lowest yield ratio in both trials, regardless of host. Overall, all three V. dahliae isolates from skullcap were able to significantly reduce yields in skullcap and Black Mitcham, the susceptible peppermint cultivar. Yield reductions in Redefined Murray, the moderately resistant peppermint cultivar, were only significant when plants were inoculated with isolate SL1-1. AUDPC and yield ratio were significantly $(P<$ $0.0001)$ and negatively associated in both the first $\left(R^{2}=0.7548\right)$ and second $\left(R^{2}=0.4138\right)$ trials. Regression analysis using data combined from both trials demonstrated a significant $(P<0.0001)$ relationship $\left(y=1.0118-0.0074 x ; R^{2}=0.5318\right)$ (Fig. 2A).

VCG analysis. The nit mutants were obtained from $V$. dahliae isolates VSP 08-33 A3 and VSP 08-33 C4. Isolate VSP 08-33 A3 exhibited moderate complementation with the VCG 2B tester strain and weak complementation with the VCG 4A tester strain. Isolate VSP 08-33 C4 exhibited strong complementation with both VCG $2 \mathrm{~B}$ and VCG $4 \mathrm{~A}$ tester strains. The nit mutants were not obtained from isolate SL1-1.

An independent VCG analysis in the laboratory of Dr. Jim Correll (University of Arkansas, Fayetteville) demonstrated that at least one of two nit mutants obtained from each of the three isolates was weakly compatible with VCG $2 \mathrm{~B}$ tester strains. However, one mutant obtained from VSP 08-33 A3 showed a weak interaction with both VCG 2A and VCG 2B tester strains, and one mutant obtained from SL1-1 showed weak complementation with VCG 1B tester strain. Because all interactions were considered weak or ambiguous, the specific VCGs of the skullcap $V$. dahliae isolates could not be determined unequivocally.

Aggressiveness assays. Overall, disease was less severe during the second trial; therefore, AUDPC data from each trial were analyzed separately (Table 1 ). The host-isolate interaction for AUDPC values was significant $(P=0.0035)$ in the first trial but not significant $(P=0.1080)$ in the second trial. The main effects of $V$. dahliae isolate and host plant were significant at $P<0.0001$ and $P=$ 0.0444 , respectively, in the second trial. The three isolates from skullcap were not significantly different from each other or the peppermint isolate when inoculated onto skullcap and Black Mitcham peppermint in both trials. All four isolates caused significantly greater mean AUDPC values than that of the potato isolate and the noninoculated control plants in both trials for Black Mitcham peppermint and in one trial for skullcap. Redefined Murray peppermint exhibited less severe symptoms in both trials, and the only isolate that caused significantly more disease and smaller yields than that of the noninoculated control plants was SL1-1. This isolate was significantly more aggressive than all other iso-
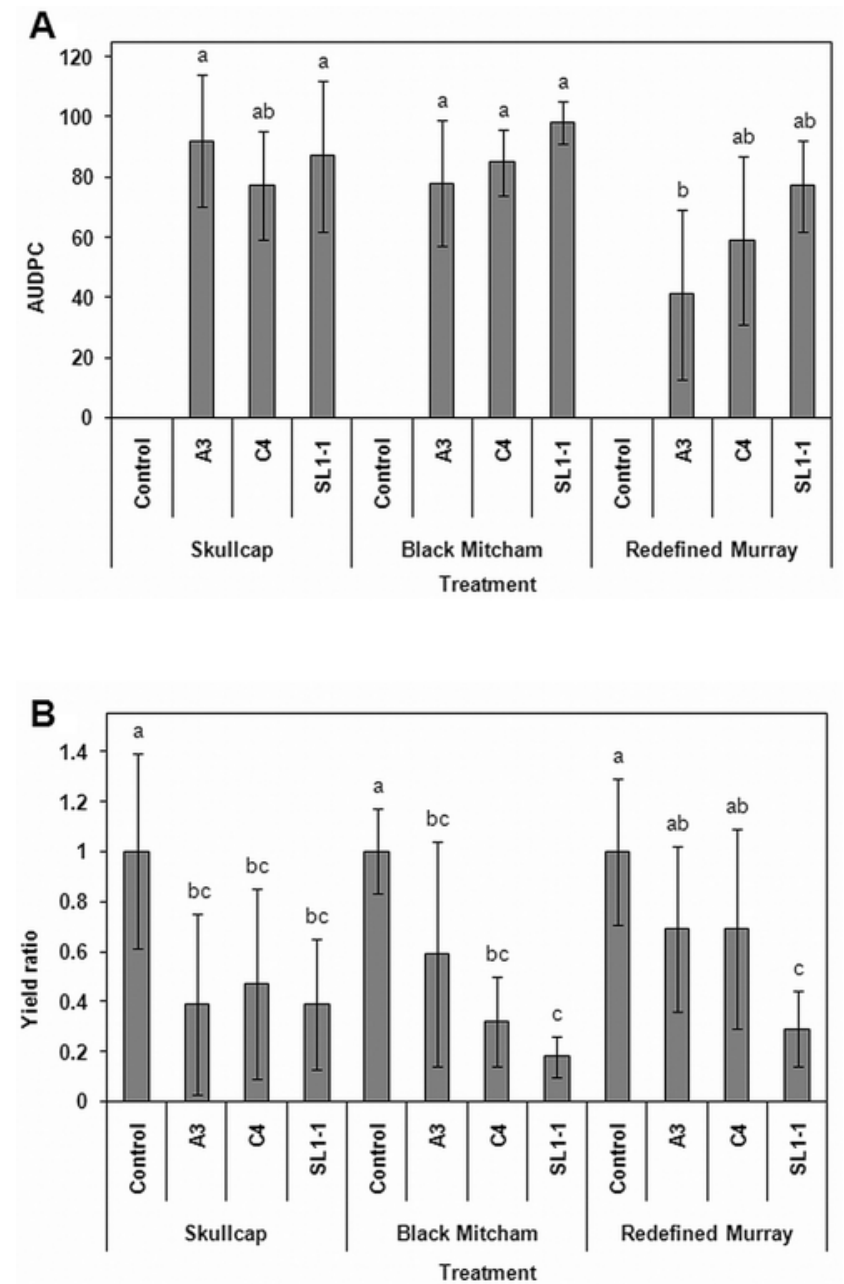

Fig. 1. A, Area under disease progress curves (AUDPC) and B, yield ratios of skullcap and peppermint ('Black Mitcham' and 'Redefined Murray') following rootdip inoculations with Verticillium dahliae isolates from skullcap (VSP 08-33 A3, VSP 08-33 C4, and SL1-1) versus a water-inoculated control treatment. Each bar represents the mean and standard deviation of six replications of each treatment combination combined over two trials. Treatments with the same letter designation were not significantly different using Tukey's honest significant difference test $(P<0.05)$. 
lates in the first trial and caused significantly greater AUDPC values than the potato isolate in the second trial.

Yield ratio data were also analyzed separately by trial (Table 1). The host-isolate interaction term was significant in the first trial $(P$ $=0.0141)$ but not in the second trial $(P=0.7042)$. Yield ratios of inoculated skullcap plants were significantly reduced by the peppermint isolate in the first trial. Although skullcap plants inoculated with $V$. dahliae isolates from skullcap resulted in reduced yields, the differences were not significant. Yield ratios of Black Mitcham peppermint plants were significantly reduced by isolates VSP 08-33 A3, SL1-1, and 109 compared with noninoculated control plants in the first trial. Redefined Murray peppermint yields were only significantly reduced by isolate SL1-1 in the first trial. The main effect of host was significant for yield during the second trial but differences among $V$. dahliae isolates were not significant. However, isolates from skullcap and peppermint generally caused reduced yield ratios in skullcap and Black Mitcham peppermint in the second trial. Plants inoculated with the potato isolate generally
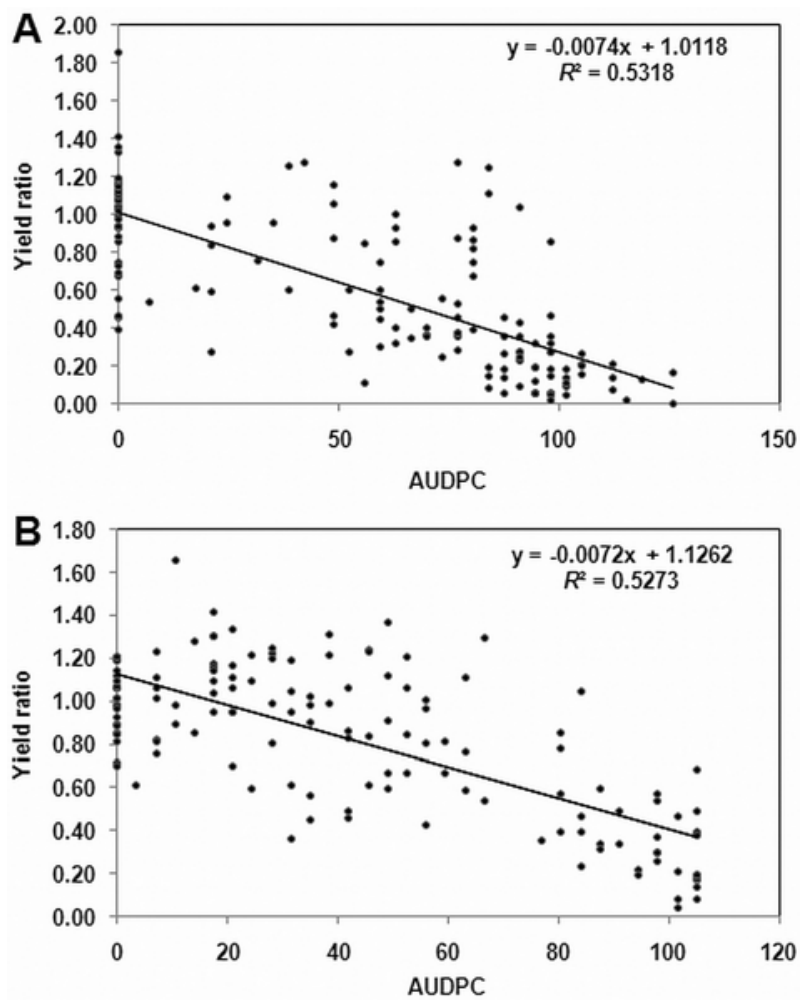

Fig. 2. Regression analyses of area under disease progress curves (AUDPC) and yield ratio in skullcap and peppermint plants following $\mathbf{A}$, root-dip inoculation with a water control treatment or Verticillium dahliae isolates from skullcap and peppermint and $\mathbf{B}$, soil-drench inoculation with a water control treatment or $\mathbf{V}$. dahliae isolates from skullcap, peppermint, and potato. Data points in each figure are combined from two trials. exhibited increased mean yield ratios in both trials. A significant $(P$ $<0.0001)$ relationship between AUDPC and yield was observed in the first trial $\left(R^{2}=0.7588\right)$, with a negative slope parameter estimate $(-0.0081)$ indicating decreasing yield ratio with increasing AUDPC. The association was not significant in the second trial $(P$ $=0.0553)$; however, when data from both trials were combined, the association between AUDPC and yield was significant at $P<$ $0.0001\left(y=1.1262-0.0072 x ; R^{2}=0.5273\right)$ (Fig. 2B).

Stem and seed assays. The three $V$. dahliae isolates from skullcap were recovered from all three inoculated hosts following root dip inoculations. Infested stems readily formed conidiophores and microsclerotia on host tissue after 7 to 10 days on moistened Whatman filter paper. The highest frequency of reisolation was from stems of Black Mitcham peppermint (93.0\%), followed by skullcap (69.4\%) and Redefined Murray peppermint (61.1\%). Isolate SL1-1 was recovered at a higher frequency than the other two isolates, including from Redefined Murray peppermint, the moderately resistant host. Following soil drench inoculations, isolates from skullcap and peppermint were reisolated from 43.8 to $81.3 \%$ of skullcap and Black Mitcham peppermint stems but only 6.3 to $43.8 \%$ of Redefined Mitcham peppermint stems. The potato isolate was only recovered once from inoculated skullcap plants.

$V$. dahliae was isolated from $5 \%$ of seed harvested from skullcap plants that had been inoculated with the peppermint isolate during the first trial but was not recovered from seed harvested from plants inoculated with any other isolates. Infected seed exhibited microsclerotia and conidiophores on the seed coat. Only one of the seeds incubated on moist Whatman filter paper germinated, and signs of $V$. dahliae infection (microsclerotia on the seed coat and conidiophore development on the seed and hypocotyls) were observed but the plant that developed from that seedling did not show symptoms of Verticillium wilt after several months of growth, harvest, and regrowth of the plant; this seed was harvested from a plant inoculated with the $V$. dahliae isolate from peppermint. Infected seed were not recovered from any skullcap plants inoculated during the second trial.

\section{Discussion}

This is the first report of $V$. dahliae infecting $S$. lateriflora in either a natural or agroecosystem. Sequencing of the ITS region of DNA confirmed the culture-based morphological identification of these isolates as V. dahliae. Completion of Koch's postulates resulted in typical Verticillium wilt symptoms (unilateral chlorosis, stunting, wilting, necrosis, and senescence) on skullcap and Black Mitcham plants inoculated with the $V$. dahliae isolates collected from skullcap. Both hosts exhibited crescent leaf-shape symptoms on new growth, which is characteristic of Verticillium wilt infection in mint. Subsequent visits to the perennial skullcap crop in 2009 resulted in the recovery of eight additional $V$. dahliae isolates from symptomatic plants. The pathogen was recovered from all vegetative plant parts, including stems, roots, and stem sap from diseased plants in the field, as well as from seed harvested from plants inoculated in the greenhouse (data not shown).

Table 1. Area under disease progress curves (AUDPC) and yield ratios of skullcap, 'Black Mitcham' peppermint, and 'Redefined Murray' peppermint following soil drench inoculations with three Verticillium dahliae isolates from skullcap (VSP 08-33 A3, VSP 08-33 C4, and SL1-1) and one V. dahliae isolate each from peppermint (109) and potato $(653)^{\mathrm{z}}$

\begin{tabular}{|c|c|c|c|c|c|c|c|c|c|c|c|c|}
\hline \multirow[b]{3}{*}{ Isolate } & \multicolumn{6}{|c|}{ AUDPC } & \multicolumn{6}{|c|}{ Yield ratio } \\
\hline & \multicolumn{2}{|c|}{ Skullcap } & \multicolumn{2}{|c|}{ Black Mitcham } & \multicolumn{2}{|c|}{ Redefined Murray } & \multicolumn{2}{|c|}{ Skullcap } & \multicolumn{2}{|c|}{ Black Mitcham } & \multicolumn{2}{|c|}{ Redefined Murray } \\
\hline & Trial 1 & Trial 2 & Trial 1 & Trial 2 & Trial 1 & Trial 2 & Trial 1 & Trial 2 & Trial 1 & Trial 2 & Trial 1 & Trial 2 \\
\hline VSP $08-33$ A 3 & $82 \mathrm{a}$ & $43 \mathrm{a}$ & $93 \mathrm{a}$ & $56 \mathrm{a}$ & $39 \mathrm{a}$ & $32 \mathrm{ab}$ & $0.61 \mathrm{ab}$ & $0.52 \mathrm{a}$ & $0.38 \mathrm{a}$ & $0.88 \mathrm{a}$ & $0.88 \mathrm{ab}$ & $1.19 \mathrm{a}$ \\
\hline VSP $08-33$ C4 & $82 \mathrm{a}$ & $45 \mathrm{a}$ & $92 \mathrm{a}$ & $45 \mathrm{a}$ & $39 \mathrm{a}$ & $29 \mathrm{ab}$ & $0.54 \mathrm{ab}$ & $0.68 \mathrm{a}$ & $0.51 \mathrm{ac}$ & $0.97 \mathrm{a}$ & $0.81 \mathrm{ab}$ & $1.01 \mathrm{a}$ \\
\hline SL1-1 & $88 \mathrm{a}$ & $56 \mathrm{a}$ & $89 a$ & $51 \mathrm{a}$ & $94 \mathrm{~b}$ & $54 \mathrm{~b}$ & $0.52 \mathrm{ab}$ & $0.79 \mathrm{a}$ & $0.29 \mathrm{a}$ & $0.95 \mathrm{a}$ & $0.39 \mathrm{~b}$ & $1.01 \mathrm{a}$ \\
\hline 109 & $100 \mathrm{a}$ & $33 a b$ & $102 \mathrm{a}$ & $53 \mathrm{a}$ & $33 \mathrm{a}$ & $28 \mathrm{ab}$ & $0.22 \mathrm{a}$ & $0.70 \mathrm{a}$ & $0.22 \mathrm{a}$ & $0.83 \mathrm{a}$ & $1.10 \mathrm{a}$ & $1.04 \mathrm{a}$ \\
\hline 653 & $11 \mathrm{~b}$ & $6 \mathrm{bc}$ & $18 \mathrm{~b}$ & $13 \mathrm{~b}$ & $21 \mathrm{a}$ & $21 \mathrm{a}$ & $1.08 \mathrm{~b}$ & $0.75 \mathrm{a}$ & $1.11 \mathrm{~b}$ & $1.03 \mathrm{a}$ & $1.24 \mathrm{a}$ & $1.33 \mathrm{a}$ \\
\hline Control & $0 \mathrm{~b}$ & $0 \mathrm{c}$ & $0 \mathrm{~b}$ & $0 \mathrm{~b}$ & $0 \mathrm{a}$ & $0 \mathrm{a}$ & $1.00 \mathrm{~b}$ & $1.00 \mathrm{a}$ & $1.00 \mathrm{bc}$ & $1.00 \mathrm{a}$ & $1.00 \mathrm{a}$ & $1.00 \mathrm{a}$ \\
\hline
\end{tabular}

${ }^{\mathrm{z}}$ Each data point is the mean of four replications. Within each column, means followed by the same letter are not significantly different based on analysis of variance and Tukey's honest significant difference test $(P<0.05)$. 
Disease symptoms and yield reductions were not as severe during the second aggressiveness trial, possibly due to minor differences in diurnal temperature variation, the amount of natural versus supplemental light, or a combination of factors. The two rootdip trials were conducted within 2 weeks, when conditions were similar. In addition, the root-dip inoculation procedure may have exposed the plants to more effective inoculum than a conidial drench applied to the soil. AUDPC and yield ratio exhibited a significant negative relationship in three of four trials and was almost significant in the fourth trial, indicating that the DSI used accurately reflected the potential impact of the disease on yield.

Peppermint, a crop susceptible to certain strains of $V$. dahliae, was grown in the affected field 6 years prior to planting skullcap. The grower indicated that the peppermint crop had developed extensive symptoms of Verticillium wilt. Another field of skullcap, which had been cropped to an apparently healthy peppermint crop 8 years prior, also showed symptoms of Verticillium wilt during the second year of skullcap production. In this study, all three isolates of $V$. dahliae collected from skullcap were highly aggressive on mint, causing severe disease. In addition, the $V$. dahliae isolate from mint was equally aggressive on skullcap, demonstrating that $V$. dahliae strains from skullcap and mint can cause severe disease on both hosts. These results suggest that skullcap and peppermint ideally should not be grown in rotation in areas where Verticillium wilt is known to occur.

The majority of $V$. dahliae isolates collected from mint belong to VCG 2B (15). Although the VCG analysis in this study could not definitively place the $V$. dahliae isolates from skullcap within a VCG, most were weakly to strongly compatible with the VCG 2B tester strains. Previous studies have found variability in complementation reactions between different VCGs, particularly with VCG 2 isolates $(26,37)$. Although it cannot be concluded definitively that the strains of $V$. dahliae affecting the skullcap crop were the same or derived from the strains affecting the previous peppermint crop, this is a distinct possibility. Further genetic analyses using recently developed microsatellites (4) indicate that all 11 isolates collected in 2008 and 2009 are the same multilocus haplotype that is predominant in infected mint sampled from the Columbia Basin (unpublished data).

Despite a broad host range, some isolates of $V$. dahliae exhibit differences in the ability to cause Verticillium wilt symptoms on certain hosts $(8,12)$. Previous studies found that $V$. dahliae isolates collected from mint are highly aggressive on mint compared with strains from other hosts $(15,16,22)$. The ability of the $V$. dahliae isolates from skullcap and mint to cause disease on both crops suggests that both hosts are susceptible to the same strains of the fungus. In contrast, a study by Fuentes-Granados and Widrlechner (21) found that strains of V. dahliae from Agastache spp. exhibited a degree of specificity to other hosts in the Lamiaceae. Strains from peppermint were not able to infect Agastache spp. and vice versa, leading the authors to conclude that peppermint and Agastache strains of $V$. dahliae were distinct. The results from these two studies suggest there is variation in aggressiveness among $V$. dahliae populations with regard to hosts in the Lamiaceae. Such variation has been observed in closely related species in the same genera; for example, Mentha $(16,24)$ and Brassica (9).

Because skullcap growers regularly save skullcap seed for future planting, it is important to determine the potential for dissemination of $V$. dahliae via true seed. Other crops, such as cotton, tomato, spinach, and lettuce, have been demonstrated to harbor seedborne $V$. dahliae in commercial seed lots, which potentially can contribute to long-distance dissemination of the pathogen and the infestation of fields $(2,17,30,40)$. In this study, $5 \%$ of seed collected from inoculated skullcap plants were infected in the first aggressiveness assay. The second aggressiveness assay did not yield any infected harvested seed. All infected seed were collected from plants inoculated with the $V$. dahliae isolate from peppermint. The relatively low incidence of $V$. dahliae detected in skullcap seed compared with other crops suggests that there may be less potential for dissemination of $V$. dahliae in skullcap seed compared with spinach and lettuce, crops that can have a high incidence of seedborne $V$. dahliae. However, a very limited amount of skullcap seed was assayed in this study, making it difficult to draw conclusions on the significance of seedborne $V$. dahliae in skullcap. Nonetheless, skullcap growers should take precautions to use pathogen-free seed, if available, because the disease threshold for Verticillium wilt in other crops, such as potato and strawberry, can be as low as 5 to $10 \mathrm{CFU} / \mathrm{g}$ soil $(34,38)$. The low incidence of seedborne $V$. dahliae detected in skullcap in this study may also have been due to the greenhouse nature of the experiments, in which there was very limited seed set. Results under field conditions may differ significantly.

In addition to true seed, skullcap growers often divide skullcap plants or use cuttings to propagate new planting material. Other studies suggest the potential for short- and long-distance movement of $V$. dahliae in vegetatively propagated crops such as mint, potato, and artichoke $(13,15,35)$. Previous studies have shown that $V$. dahliae could only be recovered from stems of Agastache and Mentha spp. in high frequency when the mother plants were infected with isolates from their respective hosts $(16,21)$. In this study, strains from skullcap and mint were able to infect stems of both hosts at high frequency, resulting in microsclerotia production on the infected plants. The $V$. dahliae strain from potato was recovered once from stems of inoculated skullcap plants. The ability of the fungus to colonize stems is important for the production of new inoculum. In addition, the microsclerotia that form in infested plant material enable the fungus to survive for long periods of time. Stem colonization can be especially important in perennial crops such as skullcap and mint, with the potential for spread of infested plant debris and soil during multiple harvests over several seasons.

The results from this study indicate that strains of $V$. dahliae collected from skullcap and peppermint plants can cause severe symptoms on both hosts. As such, skullcap and peppermint should not be grown in close rotation without other means of control (e.g., green manure crops, Brassica cover crops, or soil fumigation). The high frequency of pathogen recovery from skullcap stems suggests that there is a high potential for dissemination of $V$. dahliae during harvesting operations and in plant residues left in the fields after final cropping. Proper sanitation, including the removal of plant residues following harvest (e.g., by burning), may reduce future populations of $V$. dahliae. The potential also exists for pathogen dissemination if plants with latent infections are used for propagative material (cuttings or plant division). As such, the use of disease-free propagative material is of major importance. Fields used to propagate skullcap plants should be free of $V$. dahliae, and it may be beneficial to screen propagative material for $V$. dahliae prior to planting. Although the frequency of seed infection was low in this study, a perennial skullcap field can produce a large amount of seed over the course of several seasons, and a small proportion of infected seed could build into a potentially significant soilborne problem.

\section{Acknowledgments}

We thank anonymous skullcap growers of Washington State for in-kind support; E. Gatch for obtaining two of the isolates used in this study; R. Rowe for providing nit tester strains; and J. Correll for preliminary VCG testing of the $V$. dahliae isolates from skullcap.

\section{Literature Cited}

1. Agrios, G. N. 1997. Plant Pathology. Academic Press, San Diego, CA.

2. Allen, R. M. 1953. Verticillium wilt of cotton: studies of possible seed transmission. Phytopathology 43:585-590.

3. Altschul, S. F., Madden, T. L., Schäffer, A. A., Zhang, J., Zhang, Z., Miller, W., and Lipman, D. J. 1997. Gapped BLAST and PSI-BLAST: a new generation of protein database search programs. Nucleic Acids Res. 25:33893402 .

4. Atallah, Z. K., Maruthachalam, K., Davis, R. M., Klosterman, S. J., and Subbarao, K. V. 2009. Characterization of 22 highly polymorphic microsatellite loci in the cosmopolitan fungal plant pathogen Verticillium dahliae. Mol. Ecol. Res. 9:1460-1559.

5. Awad, R., Arnason, J. T., Trudeau, V., Bergeron, C., Budzinski, J. W., Fos- 
ter, B. C., and Merali, Z. 2003. Phytochemical and biological analysis of skullcap (Scutellaria lateriflora L.): a medicinal plant with anxiolytic properties. Phytomedicine 10:640-649.

6. Baker, K. F., and Locke, W. F. 1946. An epiphytotic of Verticillium wilt in Southern California. Plant Dis. Rep. 6:210.

7. Berry, S. Z., and Thomas, C. A. 1961. Influence of soil temperature, isolates, and method of inoculation on resistance of mint to Verticillium wilt. Phytopathology 51:169-174.

8. Bhat, R. G., and Subbarao, K. V. 1999. Host range specificity in Verticillium dahliae. Phytopathology 89:1218-1225.

9. Bhat, R. G., and Subbarao, K. V. 2001. Reaction of broccoli to isolates of Verticillium dahliae from various hosts. Plant Dis. 85:141-146.

10. Block, C. C., Senechal, N. P., and Widrlechner, M. P. 1989. First report of Verticillium wilt of Agastache rugosa caused by $V$. dahliae. Plant Dis. 73:1020.

11. Butterfield, E. J., and Devay, J. E. 1977. Reassessment of soil assays for Verticillium dahliae. Phytopathology 67:1073-1078.

12. Chang, R. J., and Eastburn, D. M. 1994. Host range of Verticillium dahliae from horseradish and pathogenicity of strains. Plant Dis. 78:503-506.

13. Cirulli, M., Bubici, G., Amenduni, M., Armengol, J., Berbegal, M., Jiménez-Gasco, M. d. M., and Jiménez-Díaz, R. M. 2010. Verticillium wilt: a threat to artichoke production. Plant Dis. 94:1176-1187.

14. Dobinson, K. F., Harrington, M. A., Omer, M., and Rowe, R. C. 2000. Molecular characterization of vegetative compatibility group 4A and 4B isolates of Verticillium dahliae associated with potato early dying. Plant Dis. 84:1241-1245.

15. Douhan, L. I., and Johnson, D. A. 2001. Vegetative compatibility and pathogenicity of Verticillium dahliae from spearmint and peppermint. Plant Dis. 85:297-302.

16. Dung, J. K. S., Schroeder, B. K., and Johnson, D. A. 2010. Evaluation of Verticillium wilt resistance in Mentha arvensis and M. longifolia genotypes. Plant Dis. 94:1255-1260.

17. du Toit, L. J., Derie, M. L., and Hernandez-Perez, P. 2005. Verticillium wilt in spinach seed production. Plant Dis. 89:4-11.

18. Evans, G., and Gleeson, A. C. 1973. Observations on the origin and nature of Verticillium dahliae colonizing plant roots. Aust. J. Biol. Sci. 26:151161

19. Farr, D. F., and Rossman, A. Y. Fungal Databases. Systematic Mycology and Microbiology Laboratory, USDA-ARS. http://nt.ars-grin.gov/fungal databases/.

20. Foster, S. 1996. Skullcap: an herbal enigma. Business Herbs May/June:1416.

21. Fuentes-Granados, R. G., and Widrlechner, M. P. 1995. Evaluation of Agastache and other Lamiaceae species for reaction to Verticillium dahliae. J. Herbs Spices Med. Plants 3:3-11.

22. Green, R. J. 1951. Studies on the host range of the Verticillium that causes wilt of Mentha piperita L. Science 113:207-208.

23. Hall, T. A. 1999. BioEdit: a user-friendly biological sequence alignment editor and analysis program for Windows 95/98/NT. Nucleic Acids Symp. Ser. 41:95-98.

24. Horner, C. E. 1954. Pathogenicity of Verticillium isolates to peppermint. Phytopathology 44:239-242.

25. Joaquim, T. R., and Rowe, R. C. 1990. Reassessment of vegetative compatibility relationships among strains of Verticillium dahliae using nitratenonutilizing mutants. Phytopathology 80:1160-1166.
26. Joaquim, T. R., and Rowe, R. C. 1991. Vegetative compatibility and virulence of strains of Verticillium dahliae from soil and potato plants. Phytopathology 81:552-558.

27. Johnson, D. A., and Cummings, T. F. 2000. Evaluation of mint mutants, hybrids, and fertile clones for resistance to Verticillium dahliae. Plant Dis. 84:235-238.

28. Johnson, D. A., and Santo, G. S. 2001. Development of wilt in mint in response to infection by two pathotypes of Verticillium dahliae and coinfection by Pratylenchus penetrans. Plant Dis. 85:1189-1192.

29. Johnson, D. A., Zhang, H., and Alldredge, J. R. 2006. Spatial pattern of Verticillium wilt in commercial mint fields. Plant Dis. 90:789-797.

30. Kadow, K. J. 1934. Seed transmission of Verticillium wilt of eggplants and tomatoes. Phytopathology 24:1265-1268.

31. Lawrence, B. M. 2007. Mint: the Genus Mentha. CRC Press, Boca Raton, FL.

32. Millspaugh, C. F. 1974. American Medicinal Plants. Dover Publications, New York.

33. National Agricultural Statistics Service. Mint Release. 2009. United States Department of Agriculture, Washington, DC

34. Nicot, P. C., and Rouse, D. I. 1987. Relationship between soil inoculum density of Verticillium dahliae and systemic colonization of potato stems in commercial fields over time. Phytopathology 77:1346-1355.

35. Omer, M. A., Johnson, D. A., and Rowe, R. C. 2000. Recovery of Verticillium dahliae from North American certified seed potatoes and characterization of strains by vegetative compatibility and aggressiveness. Am. J. Potato Res. 77:325-331.

36. Pegg, G. F., and Brady, B. L. 2002. Verticillium Wilts. CABI Publishers, Oxon, UK.

37. Strausbaugh, C. A., Schroth, M. N., Weinhold, A. R., and Hancock, J. G. 1992. Assessment of vegetative compatibility of Verticillium dahliae tester strains and isolates from California potatoes. Phytopathology 82:61-68.

38. Subbarao, K. V., Kabir, Z., Martin, F. N., and Koike, S. T. 2007. Management of soilborne diseases in strawberry using vegetable rotations. Plant Dis. 91:964-972.

39. Thompson, J. D., Higgins, D. G., and Gibson, T. J. 1994. CLUSTAL W: Improving the sensitivity of progressive multiple sequence alignment through sequence weighting, position-specific gap penalties and weight matrix choice. Nucleic Acids Res. 22:4673-4680.

40. Vallad, G. E., Bhat, R. G., Koike, S. T., Ryder, E. J., and Subbarao, K. V. 2005. Weedborne reservoirs and seed transmission of Verticillium dahliae in lettuce. Plant Dis. 89:317-324.

41. Van Der Meer, J. H. 1926. Verticillium wilt of herbaceous and woody plants. Meded. Landbouwhogesch. Wageningen 28:1-82.

42. Wehlburg, C., Alfieri, F. A., Langdon, K. R., and Kimbrough, J. W. 1975 Index of Plant Diseases in Florida. Fla. Dep. Agric. Div. Plant Ind. Bull. 11.

43. White, T. J., Bruns, T., Lee, S., and Taylor, J. 1990. Amplification and direct sequencing of fungal ribosomal RNA genes for phylogenetics. Pages 315322 in: PCR Protocols. M. A. Innes, D. H. Gelfand, J. S. Sninsky, and T. J. White, eds. Academic Press, London.

44. Wolfson, P., and Hoffmann, D. L. 2003. An investigation into the efficacy of Scutellaria lateriflora in healthy volunteers. Altern. Ther. Health Med. 9:7478 .

45. Zhang, Z., Lian, X., Li, S., and Stringer, J. L. 2009. Characterization of chemical ingredients and anticonvulsant activity of American skullcap (Scutellaria lateriflora). Phytomedicine 16:485-493. 